\title{
Variability and Significance of Labile Metals in the Offshore Mud Area of the East China Sea
}

\author{
Liu Ying \\ North China Sea Environmental Monitoring Center of \\ State Oceanic Administration \\ Qingdao, China \\ liuying@bhfj.gov.cn
}

\author{
Zhai Shikui \\ Key Laboratory of Submarine Geosciences and Prospecting \\ Techniques of Ministry of Education \\ Ocean University of China \\ Qingdao, China
}

\author{
Huo Suxia \\ North China Sea Environmental Monitoring Center of \\ State Oceanic Administration \\ Qingdao, China
}

\begin{abstract}
This paper investigated the variability of labile trace metals during recent hundred years through two cores collected in the offshore mud area of the East China Sea. The vertical variations of labile metals show much more clear human pollution records than "total" metals. The elevated values and the increasing patterns of labile $\mathrm{Pb}, \mathrm{Zn}$ estimate human pollution was much more serious since economic policy implemented at 1978 in China. Besides, the labile $\mathrm{Cu}, \mathrm{Zn}$ and $\mathrm{Pb}$ accumulate in deep depth in two cores, which are much different from "total" metals, showing post-depositional diagenesis plays an important role on the redistribution of labile metals. The results would help to reassess the impacts of contamination and also to find suitable treatment techniques for the polluted sediments.
\end{abstract}

Index Terms - the East China Sea, labile metals, human pollution records, diagenesis.

\section{I.INTRODUCTION}

Over the past several decades, huge metals have been discharged into the world's rivers and estuaries as products of rapid economy development ${ }^{[1-3]}$. When elevated, trace metals can exert toxic effects, including those biologically essential. The enrichment of trace metals in the environment can result from both anthropogenic activities and natural processes ${ }^{[4,5]}$. Some speciation of metals generate naturally through the weathering of rocks, which are often enriched in refractory minerals and do not imply high toxicity to ecology. Only speciation that could be easily transferred is toxic to environment, mostly belongs to human pollution products. Therefore, instead of the total metals, the study of metal speciation is a key indication for sediment pollution and biology risk.

At the same time sequential extraction procedures have received increased attention, others have argued for single 'non-selective' extractions which target a group of labile phases ${ }^{[6-8]}$. In addition to extracting a high percent of the components in surface coatings with minimal structural lattice damage, single non-residual digestion is full of advantages, such as cost-effective, rapid, requires minimal technical expertise, reduces the potential for compounding experimental error from one step to another that can occur in sequential procedures, and dangerous acids like $\mathrm{HClO}_{4}$ and $\mathrm{HF}$ are not required ${ }^{[9]}$.

Dilute $\mathrm{HCl}$ is one of the most widely used reagents to isolate the non-residual phase of a variety of solid environmental media ${ }^{[10,11]}$. It could extract the labile speciation completely, with minimal dissolution of the alumino-silicate lattice ${ }^{[9]}$. Moreover, the elevated of labile metals extracted from the sediment through $1 \mathrm{M} \mathrm{HCl}$ match well with the mortality of calms exposed to the sediment, implying significant role on biology ${ }^{[12]}$.

As the "sink" of terrestrial sediment, mud areas in the East China Sea (ECS) play an important role on the study of landocean interaction and material flux. Since the "dilution" of unpolluted huge sediment from the Yangtze River, the relative ratios of metal content induced by human activity to total metals are low ${ }^{[2]}$, and it is hard to identify human pollution records through total metals. Hence, this paper conducts a systematic analysis on labile metals of two cores in the mud area of ECS, and the primary aim of the investigation is to characterize the extents and trends of labile trace metals over the last one hundred years. We will then assess the possible influencing factors and significance of labile metals .

\section{MATERIALS AND METHODS}

\section{A. Study Area and Sampling Sites}

The sediment of offshore mud area is mainly from the Yangtze River, the third largest river in the world. Sampling locations in the ECS are presented in Fig. 1. Two cores were collected in the offshore mud area of the ECS on cruises of R/V Dong Fang Hong 2 in June 2006. Both of the two sites are in the middle of the mud area, one (site 16) at the Yangtze River Estuary Mud Area, and one (site 31) at the Min-Zhe 
Coastal Mud Area, with core length $1.59 \mathrm{~m}$ and $1.48 \mathrm{~m}$ respectively.

\section{B. Analytical Methods}

The two cores were subsampled in $2.0 \mathrm{~cm}$ interval and samples were obtained for determination of grain size, dating, total and labile metal concentration.

1) Grain Size

Grain size was measured after the pretreatment with $\mathrm{H}_{2} \mathrm{O}_{2}$ and $\left(\mathrm{NaPO}_{3}\right)_{6}$, and allowed to react for at least 24 hours respectively. Subsequently, samples were dispersed and homogenized using ultrasound, and then tested through the laser particle size analyzer (Model: Mastersizer 2000).

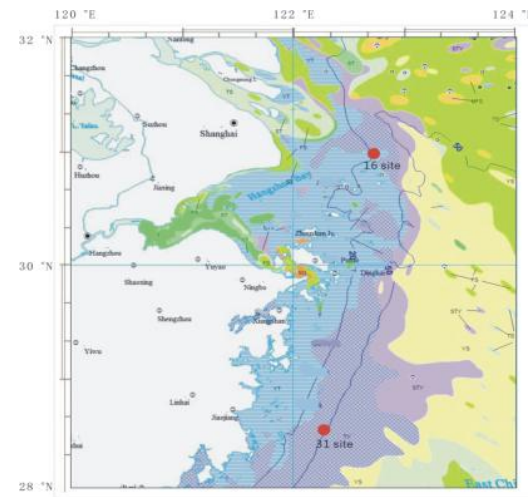

Fig. 1 Sampling sites selected in the ECS

\section{2) Dating}

The two cores were dated using an Ortec HP Ge GWL series well type coaxial low background intrinsic germanium detector. ${ }^{210} \mathrm{~Pb}$ and ${ }^{137} \mathrm{Cs}$ was determined by gamma emissions at $46.5 \mathrm{keV}$ and $661.6 \mathrm{ke} \mathrm{V}$, and ${ }^{226} \mathrm{Ra}$ by $295 \mathrm{keV}$ and 352 $\mathrm{keV}$ gamma rays emitted by the daughter isotope ${ }^{214} \mathrm{~Pb}$ following 3 weeks of storage in sealed containers to allow radioactive equilibration. ${ }^{210} \mathrm{Pbex}$ was calculated by subtracting ${ }^{226} \mathrm{Ra}$ activities from the total ${ }^{210} \mathrm{~Pb}$ activities. The relative error for this method was below $10 \%$.

\section{3) Metal Determination}

For each sample, sediments were air-dried at room temperature $\left(<30^{\circ} \mathrm{C}\right)$ and sieved through a $200-\mu \mathrm{m}$ sieve to remove root and shell fragments, then grounded and dried at $105^{\circ} \mathrm{C}$.

For total metals, samples were digested with mixed acid $\left(\mathrm{HNO}_{3}: \mathrm{HF}, 10: 1\right)$ in multiwave digestion (Perkin Elimer, USA). Then Fe and Mn were determined by ICP-AES (Perkin Elimer, OPTIMA 4300, USA), while $\mathrm{Cu}, \mathrm{Zn}, \mathrm{Pb}$ and $\mathrm{Sc}$ were determined by ICP-MS (Agilent 7500c, USA).

Determination of labile metals was based on the method by Sutherland et al. ${ }^{[9]}$ and Snape et al. ${ }^{[13]}$. For each sample, $20 \mathrm{ml}$ $1 \mathrm{M} \mathrm{HCl}$ solution was added to $0.2 \mathrm{~g}$ sediment $(1: 100 \mathrm{w} / \mathrm{v})$. Through trials of different extraction time, we found $24 \mathrm{~h}$ shaking time could make sure labile speciation completely be extracted for sediment in the mud area of ECS, and reach nearly equilibrium concentration ${ }^{[14]}$.The solution would be centrifuged at 4000rds, then the supernatant was decanted to a polyethylene bottle. All the supernatant was determined on ICP-AES (Perkin Elimer, OPTIMA 4300, USA) for labile Fe, $\mathrm{Mn}$ and ICP-MS (Agilent 7500c, USA) for labile $\mathrm{Cu}, \mathrm{Zn}, \mathrm{Pb}$.

\section{RESULTS AND DISCUSSIONS}

\section{A. Geochronology and Sedimentary Characteristic}

Core 16 is dominated by clayed silt with abrupt silt and sand intervals, effected by tide and river flood, especially storm and flood events ${ }^{[15,16]}$. ${ }^{210}$ Pbex profile shows an approximately exponential decline with depth in core 16 (Fig. 2), despite some fluctuations in certain parts suggesting variations in sediment accretion over time, which may increase the dating uncertainty. However the ${ }^{137} \mathrm{Cs}$ activity vs. depth bio-plot of core 16 shows distinct peaks in activity corresponding to periods of peak ${ }^{137} \mathrm{Cs}$ fallout in 1964. Considering the sedimentary environment of core 16 and the results of other researchers ${ }^{[2,17]}$, we find the dating by ${ }^{137} \mathrm{Cs}$ is more reasonable here. As shown in Fig. 2, the core 16 is deposited during the interval from 1954 to 2003, with an average constant sedimentation rate of $3.27 \mathrm{~cm} \mathrm{yr}^{-1}$.

The fine-grained sediment of core 31 is composed of clayed silt, and its down-core variability is small, which indicates stable sedimentary environment here. ${ }^{210} \mathrm{~Pb}_{\mathrm{ex}}$ and ${ }^{137} \mathrm{Cs}$ determination results are in good agreement (Fig. 2), indicating core 31 is deposited during the interval from 1822 to 2003, with an average constant sedimentation rate of $0.82 \mathrm{~cm} \mathrm{yr}^{-1}$.
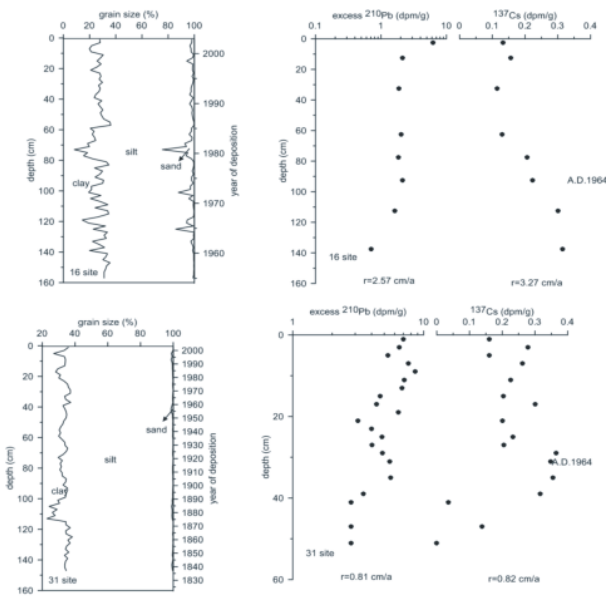

Fig. 2 Sedimentary characteristics and dating of core 16 and 31

\section{B. Distribution of Total Metals}

In this study, $\mathrm{Sc}$ is selected for normalization as proxy for grain size since it is moderately or strongly correlated with residual minerals. Profiles of Sc-normalized metal ratios vs. depth and age are plotted in Fig. 3. The ratios of $\mathrm{Cu}$ and $\mathrm{Zn}$ to $\mathrm{Sc}$ in cores remain variable with depth such as grain size (Fig. 2), which might be influenced by hydrodynamic changes. Otherwise, the content of total $\mathrm{Pb}$ is constant in both two cores, showing indistinct human pollution records. 


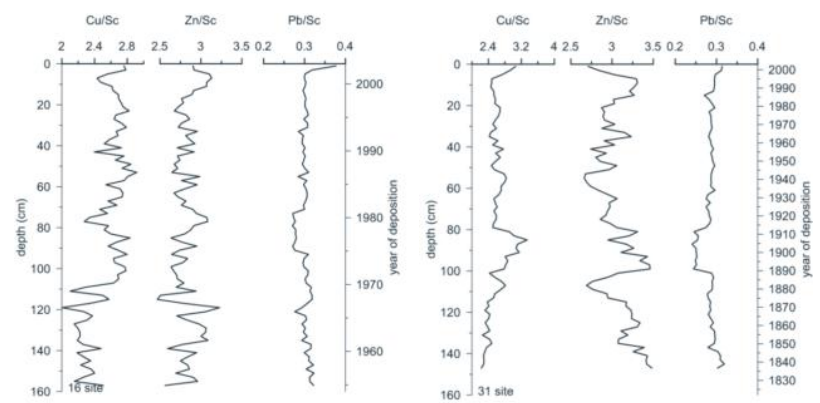

Fig.3. Profiles of ratios of total metals to Sc in the sediment cores

\section{Distribution of Labile Metals}

Table 1 shows the average concentrations of labile metals collected from the sites during the years of 1954 2003 and 1985 2003 respectively. During the same depositional time (Tab. 1), concentrations of labile $\mathrm{Zn}$ and $\mathrm{Pb}$ in core 31 estimate higher values than in core 16 , while labile $\mathrm{Cu}$ is reversed. And compared with statistical data during years of $1954 \sim 2003$, labile $\mathrm{Zn}$ and $\mathrm{Pb}$ are increasing obviously since 1985 A.D..

Tab. 1. Average concentrations of labile trace metals in the sediment cores

\begin{tabular}{ccccccc}
\hline & \multicolumn{3}{c}{$1954-2003(\mathrm{mg} / \mathrm{kg})$} & \multicolumn{3}{c}{$1985-2003(\mathrm{mg} / \mathrm{kg})$} \\
\cline { 2 - 7 } Core 16 & $\mathrm{Cu}$ & $\mathrm{Zn}$ & $\mathrm{Pb}$ & $\mathrm{Cu}$ & $\mathrm{Zn}$ & $\mathrm{Pb}$ \\
Core 31 & 18.57 & 28.93 & 20.49 & 17.51 & 31.01 & 21.65 \\
\hline
\end{tabular}

While the total metal profiles mostly remain constant, strong profiles for labile trace metals in two cores are observed (Fig. 4). Concentrations of labile $\mathrm{Pb}$ and $\mathrm{Zn}$ increased abrupt since 1985 in two cores, showing unexpected flux such as human pollution. Stable increasing profiles downward with depth are pronounced in the two cores, which requires further discussion for the cause.

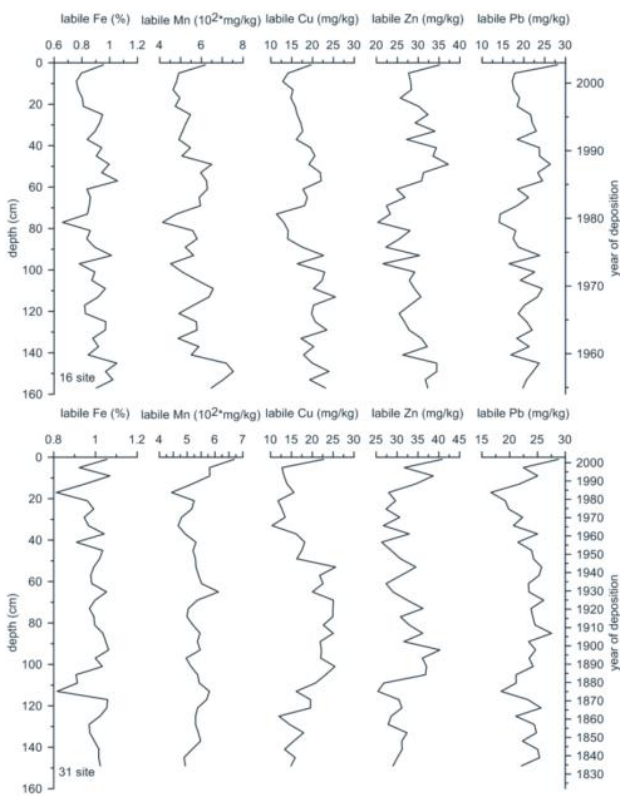

Fig. 4. Profiles of labile metals in the sediment cores

\section{Statistical Result}

In order to study the inter-elemental associations, the correlation coefficients of the labile metals were computed for the two cores separately (Tab. 2). The very low correlations of sand and mud with labile metals reveal that labile metals have different enrichment mechanism from total metals, which mostly obey "grain size controlled rule" $"[18]$.

The stronger correlations of Fe, Mn vs. labile metals are observed which indicating the adsorption of Fe-Mn chemical compound to labile metals. To compare, Fe exhibits stronger correlation with labile trace metals than $\mathrm{Mn}$ in both two cores, indicating the adsorption by amorphous Fe-oxyhydroxides is better than Mn-oxyhydroxides ${ }^{[19]}$. The association of $\mathrm{Pb}$ and $\mathrm{Zn}$ may reflect the same sources and geochemical behaviors.

Tab. 2. Correlation coefficient matrix $\left(\mathrm{R}^{2}\right)$ of labile metals in the sediment

\begin{tabular}{cccccccc}
\multicolumn{7}{c}{ cores } \\
\hline & $\mathrm{Cu}$ & $\mathrm{Zn}$ & $\mathrm{Pb}$ & $\mathrm{Fe}$ & $\mathrm{Mn}$ & sand & mud \\
\hline $\mathrm{Core} 16$ & & & & & & & \\
$\mathrm{Cu}$ & 1.00 & & & & & & \\
$\mathrm{Zn}$ & $0.47^{* *}$ & 1.00 & & & & & \\
$\mathrm{~Pb}$ & $0.67^{* *}$ & $0.79^{* *}$ & 1.00 & & & & \\
$\mathrm{Fe}$ & $0.64^{* *}$ & $0.67^{* *}$ & $0.79^{* *}$ & 1.00 & & & \\
$\mathrm{Mn}$ & $0.61^{* *}$ & $0.51^{* *}$ & $0.58^{* *}$ & $0.74^{* *}$ & 1.00 & & \\
$\mathrm{Sand}$ & -0.25 & $-0.37^{*}$ & $-0.34^{*}$ & -0.19 & $-0.32^{*}$ & 1.00 & \\
mud & 0.25 & $0.37^{*}$ & $0.34^{*}$ & 0.19 & $0.32^{*}$ & $-1.00^{* *}$ & 1.00 \\
$\mathrm{Core} 31$ & & & & & & & \\
$\mathrm{Cu}$ & 1.00 & & & & & & \\
$\mathrm{Zn}$ & $0.46^{* *}$ & 1.00 & & & & & \\
$\mathrm{~Pb}$ & $0.44^{* *}$ & $0.55^{* *}$ & 1.00 & & & & \\
$\mathrm{Fe}$ & 0.15 & $0.42^{* *}$ & $0.70^{* *}$ & 1.00 & & & \\
$\mathrm{Mn}$ & 0.23 & 0.23 & 0.11 & 0.16 & 1.00 & & \\
$\mathrm{Sand}$ & -0.15 & -0.02 & -0.31 & $-0.38^{*}$ & 0.15 & 1.00 & \\
mud & 0.15 & -0.02 & 0.31 & $0.38^{*}$ & -0.15 & $-1.00^{* *}$ & 1.00 \\
\hline
\end{tabular}

\section{DISCUSSION}

Generally, the sediment cores reveal lower concentrations of metals in deep depth, while increasing concentrations in upper sediments for much more serious worldwide human pollution recently ${ }^{[20-23]}$. Therefore, trace metals are important indexes to researches concerning sediment sources, geochemical processes and human influences. However, is the vertical profile of metals in sediment cores a reliable predictor, and does the deeper, uncontaminated sediment keep the way it was after many years of burial?

\section{A. labile metals and human pollution records}

As the relative ratios of metals induced by human pollution to natural background are too low, it is difficult to record human activities by total metals ${ }^{[2,3]}$. Especially the large sediment discharge and the "dilution" of silica minerals from Yangtze River, total metals show no significant feature of human pollution in ECS.

In this paper, considering the elevated values and the strong increasing patterns of labile $\mathrm{Pb}$ and $\mathrm{Zn}$ since 1978 A.D., we estimate human pollution is much more serious since economic policy implementation of China, which is common conclusion recently. As data above, the Yangtze River Estuary has higher total metals and relative lower labile metals than Min-Zhe coastal mud area, which estimated higher risk potential level in the Min-Zhe coastal mud area. Fe-oxyhydroxides and Mn- 
oxyhydroxides adsorption are the main factor for labile metal enrichment, otherwise grain size for total metals. Due to the more stable environment, the Min-Zhe coastal mud area may has enhanced organic matters and Fe-Mn oxyhydroxides, which adsorbs more labile metals.

\section{B. labile metals and diagenesis}

Compared to the constant profile of total metals, the enrichment of labile metals at deep depth is obvious for both two cores. Similar distributions of labile trace metals were observed by Ayyamperumal et al. ${ }^{[24]}$ and Homes et al. ${ }^{[25]}$. First of all, we can exclude the factor of material source, for the unchanging sediment supply of the Yangtze River and weathering conditions at its flow domain in recent hundreds of years. Meanwhile, Hu et al. ${ }^{[26]}$ found the enrichment of AVS at subsurface of the cores collected from the Yangtze Estuary mud area and Min-Zhe coastal mud area, which is much close with the patterns of labile metals in Fig. 4.

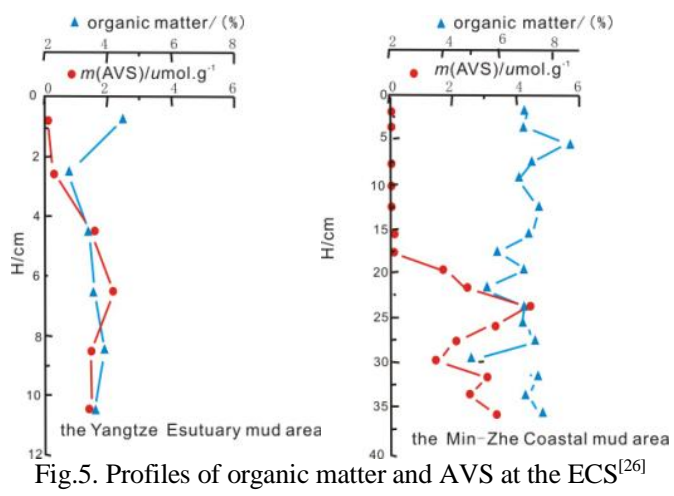

As we lack the data of AVS of core 16 and core 31, we consider the substituent of $\mathrm{Fe}$, for the two are co-existed at subsurface sediment as pyrite. Figure 6 shows the scatters of $\mathrm{Fe}$ vs. labile metals in the sediment cores, which indicates the mostly positive correlation of $\mathrm{Fe}$ with $\mathrm{Cu}, \mathrm{Zn}$ and $\mathrm{Pb}$. It may suggests that the oxidation of organic matter makes labile metals to transfer downward, and exists as sulfide like $\mathrm{Fe}$ as pyrite in the deep depth.

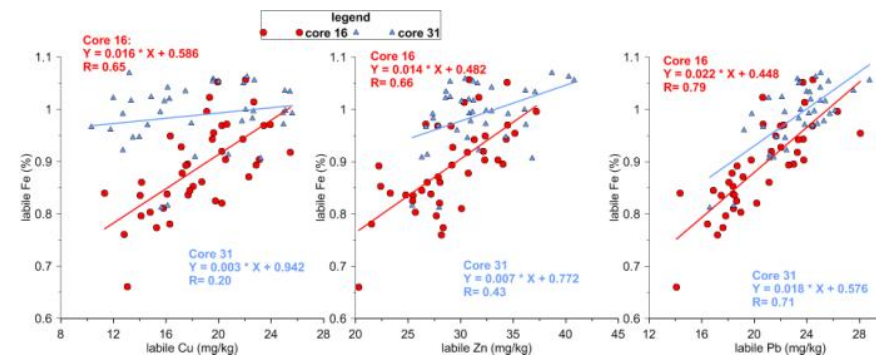

Fig. 6. Scatter plots of Fe vs. labile metals in the sediment cores

Further investigation needs to continue for postdepositional processes, such as the phenomenon exists commonly or not, the extent of element accumulation, and the environmental factors on the accumulation stability et al.. If we could make sure the mechanism of labile metal enrichment after deposition and find its environmental factors, the results would help to re-assess the impacts of contamination. Moreover, some remedial measures can also be proposed for strategic pollution control and management in the ECS region in the future.

\section{CONCLUSIONS}

This study focuses on labile metals of two cores in the mud area at the East China Sea, using the technique of $\mathrm{HCl}$ extraction. By removing the influence of the natural background, the labile metals show obvious increasing patterns since 1980 s, indicating clear human pollution records.

The higher labile metal contents of the Min-Zhe coastal mud area than the Yangtze Estuary mud area estimates the labile metals accumulate easily in stable sedimentary environment such as the Min-Zhe coastal mud area, even the latter is much close to the terrestrial sources. Other phenomenon is the enrichment of labile metals at the deep depth of two cores, coexisted with the same distribution patterns of Fe and AVS. It seems that the enrichment of labile metals consistently reflect early diagenesis process, such as oxidation of sulphate and formation of sulfide.

\section{ACKNOWLEDGMENT}

This research was supported by Public Science and Technology Research Funds Projects of Ocean NO. 201105003-2 and MRE Grant NO. 201116. We thank Dong Aiguo and Yu Zenghui for their help in the field, and Zhang Aibin for valuable discussions and help with the labile metals analyses.

\section{REFERENCES}

[1] Chen, Z., Kostaschuk, R.M. and Yang, M. (2001). Cases and solutions: heavy metals on tidal flats in the Yangtze estuary, China. Environmental Geology. 40(6), 742-749.

[2] Chen, Z., Satio, Y. and Kanai, Y. (2004). Low concentrations of heavy metals in the Yangtze estuarine sediments, China: a diluting setting. Estuarine, Coastal and Shelf Science. 60(1), 91-100.

[3] Jayaprakash, M., Jonathan, M.P. and Srinivasalu S. (2008). Acid-leachable trace metals in sediments from an industrialized region(Ennore Creek) of Chennai City, SE coast of India: An approach towards regular monitoring. Estuarine, Coastal and Shelf Science. 76, 692-703.

[4] Forstner, U. and Wittmann, G.T.W. (1979). Metal pollution in the aquatic environment. Springer-Verlag, Berlin, Heidelberg, New York.

[5] Veena, B., Radhakrishnan, C.K. and Chacko, J. (1997). Heavy metal induced biochemical effects in an estuarine teleost. Indian J. Mar. Sci. 26, 74-78.

[6] Agemian, H. and Chau, A.S.Y. (1976). Evaluation of extraction techniques for the determination of metals in aquatic sediments. Analyst. 101, 761-767.

[7] Malo, B.A. (1977). Partial extraction of metals from aquatic sediments. Environ. Sci. Technol. 11, 277-282.

[8] Chester, R. and Voutsinou, F.G. (1981). The initial assessment of trace metal pollution in coastal sediments. Mar. Poll. Bull. 12, 84-91.

[9] Sutherland, R.A. (2002). Comparison between non-residual Al, $\mathrm{Co}, \mathrm{Cu}, \mathrm{Fe}, \mathrm{Mn}, \mathrm{Ni}, \mathrm{Pb}$ and $\mathrm{Zn}$ released by a three-step sequential extraction procedure and a dilute hydrochloric acid leach for soil and road deposited sediment. Applied Geochemistry. 17, 353-365. 
[10] Steele, M.C., Pichtel, J. (1998). Ex-situ remediation of a metalcontaminated Superfund soil using selective extractants. J. Environ. Engin. 124, 639-645.

[11] Sutherland, R.A. (2000). Depth variation in copper, lead, and zinc concentrations and mass enrichment ratios in soils of an urban watershed. J. Environ. Qual. 29, 1414-1422.

[12] Lu, X.Q., Werner, I. and Young, T.M. (2005). Geochemistry and bioavailability of metals in sediments from northern San Francisco Bay. Environment International. 31, 593-602.

[13] I Snape, R.C. Scouller, S.C. Stark et al.. Characterisation of the dilute $\mathrm{HCl}$ extraction method for the identification of metal contamination in Antarctic marine sediments[J]. Chemosphere, 2004, 57: 491-504.

[14] Liu, Y., Zhai, S.K. (2010). The extraction method and characterisation of environmental labile metals in mud area of the East China Sea. Proceedings of the forth young scientist forum by the Chinese Society of Oceanography. pp. 217-226.

[15] Yang Z.S., Chen X.H. (2007). Centurial high resolution records of sediment grain-size variation in the mud area off the Changjiang (Yangtze River) Estuary and its influencial factors. Quaternary Science. 27(5), 690-699.

[16] Liu Y., Zhai S. K., Li J. (2010a). Depositional records in the mud areas of Changjiang Estuary and Off Min-Zhe Coast and their influence factors. Marine Geology and Quaternary Geology China. 30(5), 1-10.

[17] Huh, C. A. (1999). Sedimentation dynamics in the East China Sea elucidated from $210 \mathrm{~Pb}, 137 \mathrm{Cs}$ and $239,240 \mathrm{Pu}$. Marine Geology. 160, 183-196.

[18] Zhao, Y.Y. and Yan M.C. (1994). Geochemistry of sediments of the china shelf sea. China Science Press. pp.179-183.
[19] Gobeil, C., Macdonald, R. W. and Sundby, B. (1998). Diagenetic separation of cadmium and manganese in suboxic continental margin sediments. Geochimica et Cosmochimica Acta. 61(21), 4647-4654.

[20] Langston, W.J., Burt, G.R. and Pope, N.D. (1999). Bioavailability of Metals in Sediments of the Dogger Bank(Central North Sea): A Mesocosm Study. Estuarine, Coastal and Shelf Science. 48, 519-540.

[21] Sutherland, R.A. (2000a). Bed sediment-associated trace metals in an urban stream, Oahu, Hawaii. Environ. Geol. 39, 611-627.

[22] Borgmann, U. and Norwood, W. P. (2002). Metal bioavailability and toxicity through a sediment core. Environmental Pollution. 116, 159-168.

[23] Guo, Z.G. (2007). The sedimentary fluxes of polycyclic aromatic hydrocarbons in the Yangtze River Estuary coastal sea for the past century. Science of the Total Environment. 386, 3341.

[24] Ayyamperumal, T., Jonathan, M. P. and Srinivasalu S. (2006). Assessment of acid leachable trace metals in sediment cores from River Uppanar, Cuddalore, Southeast coast of India. Environmental Pollution. 143, 34-45.

[25] Homes, M.M., Stevens, R.L. and Boer, W. (2006). Pollution history of heavy metals on the Portuguese shelf using $210 \mathrm{~Pb}$ geochronology. Science of the Total Environment. 367, 466480

[26] Hu, L., Liu, S.M., Ren, J.L. et al. (2009). Research of the distribution of AVS in the offshore sediment of the East China Sea. Marine Environmental Science China. 28(5), 482-486. 